\title{
Review
}

\section{Future possibilities in the prevention of breast cancer Breast cancer prevention trials Jack Cuzick}

\author{
Imperial Cancer Research Fund, London, UK
}

\begin{abstract}
The available results from breast cancer chemoprevention trials are reviewed. Four trials using tamoxifen have been performed, of which three have reported efficacy results. A fifth trial using raloxifene has also been reported. The largest tamoxifen trial showed approximately 50\% reduction in breast cancer incidence in the short term, but the two smaller trials did not find any reduction. Greater agreement exists for side effects; incidences of thromboembolic disease and endometrial cancers are raised approximately threefold when tamoxifen is used for 5 years. The possible reasons for the discrepancy in breast cancer reduction are explored. A review of trial parameters does not clearly explain this difference, and a meta-analysis indicates that all results are compatible with a $40 \%$ reduction in short-term incidence. Several important questions remain regarding the clinical implications of this result, including the effect on mortality, the appropriate risk groups for chemoprevention and the long-term effects on incidence. Continued follow up of these trials is crucial for resolving these issues.
\end{abstract}

Keywords: breast cancer, chemoprevention, meta-analysis, raloxifene, tamoxifen

\section{Introduction}

Following the observation that tamoxifen reduced the incidence of contralateral breast cancer when used in the adjuvant setting, it was suggested that prevention of breast cancer in high-risk women might also be possible with this drug $\left[1^{\bullet}, 2^{\circ}\right]$. A pilot study was initiated under the auspices of the United Kingdom Coordinating Committee for Cancer Research at the Royal Marsden Hospital (RMH). As a result of the favourable compliance data and lack of unexpected toxicities in the $\mathrm{RMH}$ trial, the United Kingdom Coordinating Committee for Cancer Research launched its main trial, the International Breast Cancer Intervention Study (IBIS) in 1992.Subjects were first enrolled in Australia, because the
UK Medical Research Council were concerned about hepatic toxicity of tamoxifen in some strains of rats and their concerns delayed the onset of the study in the UK until November 1993. A similar trial was initiated in the USA in 1992 under the auspices of the National Surgical Adjuvant Breast Project (NSABP) [3*]. All trials were placebo-controlled studies of 5 years of tamoxifen administration.

Three studies have reported early results on breast cancer reduction. In the largest study, the NSABP Prevention 1 trial [ $3^{\circ}$ ], an almost $50 \%$ reduction in new tumours was found. This result is very similar to that which was expected from the adjuvant studies [4 $\left.{ }^{\circ}\right]$, and led to the

$\mathrm{Cl}=$ confidence interval; $\mathrm{ER}=$ oestrogen receptor; HRT = hormone replacement therapy; OR = odds ratio; IBIS = International Breast Cancer Intervention Study; MORE = Multiple Outcomes of Raloxifene Evaluation; NSABP $=$ National Surgical Adjuvant Breast Project; RMH $=$ Royal Marsden Hospital. 
early stopping, unblinding and curtailment of the American trial. However, the preliminary results of the $\mathrm{RMH}$ trial $\left[5^{\circ}\right]$ and the Italian trial $\left[^{\circ}\right.$ ] did not indicate any reduction in breast cancer incidence. These trials remain blinded at the individual level and further follow up is continuing.

The present review examines the differences between these trials, and assesses factors that might explain the differences in results. The IBIS trial is not scheduled to complete recruitment until the end of 2000 , and results on the reduction of breast cancer incidence are not available. However, some demographic data are available from this trial, and thus we can make some comparisons between it and the three other tamoxifen prevention trials $\left[3^{\bullet}, 5^{\bullet}, 6^{\bullet}\right]$. A fifth trial (Multiple Outcomes of Raloxifene Evaluation; MORE), designed primarily to look at the value of 3 years of use of the new selective oestrogen receptor modulator raloxifene in preventing osteoporosis, has also recently reported on breast cancer prevention [ $\left.7^{\circ}\right]$, and is also reviewed.

\section{Demography}

The entry criteria and basic characteristics of the five trials are summarized in Tables 1 and 2 . The number of subjects entered into the NSABP trial $\left[3^{\circ}\right]$ is about the same as that recruited into all of the IBIS, $\mathrm{RMH}\left[5^{\circ}\right]$, Italian [6 $\left.6^{\circ}\right]$ and

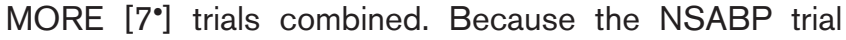
recruited quickly, there is already a median follow up of 55 months, compared with 30 months for the Italian study and (currently) 30 months for IBIS. The smaller RMH study has the longest median follow up (70 months).

The age ranges for entry were similar among the tamoxifen trials, although a few women aged below 35 years were entered into the $\mathrm{RMH}$ trial and a few who were aged over 70 years were entered into the NSABP trial. The median age of entry was lower for the RMH and IBIS trials, and more women were below the age of 50 years at entry. The MORE trial entered only postmenopausal women under the age of $\mathbf{8 0}$ and had a much older median age at entry.

The differences in age at entry are related to different entry criteria for the five trials. The RMH and IBIS trials entered mainly subjects with a family history of breast cancer (96 and $91 \%$, respectively, had at least one first-degree relative with breast cancer). Indeed, in the $\mathrm{RMH}$ trial $36 \%$ of patients were at risk sufficient to be potential carriers of BRCA1 or BRCA2 mutations. In IBIS $20 \%$ of subjects had two or more first-degree relatives with breast cancer and the NSABP trial had 19\%.

Because of concerns about tamoxifen-associated endometrial cancer, the Italian trial admitted subjects only if they had had a hysterectomy. Approximately half of the women had also had an oophorectomy, some at a relatively young age, so that many of the women entered into this trial were at a lower than average risk for breast
Table 1

\begin{tabular}{|c|c|c|c|}
\hline Trial & Population & $\begin{array}{c}\text { Agent } \\
\text { (versus placebo), } \\
\text { dose (mg/day) }\end{array}$ & $\begin{array}{c}\text { Intended } \\
\text { duration of } \\
\text { treatment (years) }\end{array}$ \\
\hline $\mathrm{RMH}\left[5^{\circ}\right]$ & $\begin{array}{l}\text { High risk } \\
\text { Family history }\end{array}$ & Tamoxifen, 20 & $5-8$ \\
\hline NSABP [3"] & $1.6 \% 5$-year risk & Tamoxifen, 20 & 5 \\
\hline Italian [6 $\left.6^{\circ}\right]$ & $\begin{array}{l}\text { Normal Risk } \\
\text { Hysterectomy }\end{array}$ & Tamoxifen, 20 & 5 \\
\hline IBIS & $>$ Twofold risk & Tamoxifen, 20 & 5 \\
\hline MORE [7] & $\begin{array}{c}\text { Normal risk } \\
\text { Osteoporotic } \\
\text { Postmenopausal }\end{array}$ & $\begin{array}{l}\text { Raloxifene, } \\
60 \text { or } 120\end{array}$ & 3 \\
\hline
\end{tabular}

cancer. The entry criteria for NSABP were calculated according to the Gail model, which takes into account family history (but not the age of the affected relative), number of breast biopsies and hormonal risk factors. All women aged 60 years or more were eligible and women less than 60 had to have a 5-year risk of breast cancer equivalent to that in a woman of 60 years. The entry criteria for the IBIS trial are based on family history, benign breast disease and nulliparity. A range of options for entry was used to approximate a twofold risk compared to the normal populkation for age in the range 45-70 years, a fourfold risk for age in the range 40-44 years, and a 10fold risk for age in the range 35-39 years. Details were provided by Cuzick [8]. Although pathological and endocrine risk factors were allowed, in practice the large majority of subjects were entered because of a history of a young close relative with breast cancer. This was also true of the RMH trial, but was less true for the NSABP study, in which hormonal risk factors and breast biopsies were more important entry criteria.

The MORE trial was designed to examine osteoporosis primarily, and no risk factors for breast cancer were required for entry. Raloxifene was given daily at two doses (60 and $120 \mathrm{mg}$ ), and these groups were combined for analysis, so there were about twice as many patients in the treated group (5129 versus 2576).

\section{Compliance}

Compliance is crucial for maintaining power in prevention studies. Table 3 shows that this was remarkably good for all studies, and was around $70-75 \%$ for tamoxifen, although comparisons between trials are not valid because of the different ways of presenting compliance data (crude percentages, actuarial curves, percentage of prescribed medication taken). Effective sample size is proportional to the square of compliance rates, so that even with $75 \%$ 
Table 2

\begin{tabular}{|c|c|c|c|c|c|c|}
\hline \multirow[b]{2}{*}{ Trial } & \multirow[b]{2}{*}{ Total randomized } & \multirow[b]{2}{*}{$\begin{array}{l}\text { Median follow up } \\
\text { (months) }\end{array}$} & \multicolumn{4}{|c|}{ Cancers } \\
\hline & & & Total & $\begin{array}{l}\text { Tamoxifen/ } \\
\text { raloxifene }\end{array}$ & Placebo & OR \\
\hline $\mathrm{RMH}\left[5^{\circ}\right]$ & 2471 & 70 & 70 & 34 & 36 & 0.94 \\
\hline NSABP [3] & 13388 & 57 & 368 & 124 & 244 & 0.51 \\
\hline Italian [6 $\left.6^{\bullet}\right]$ & 5408 & 46 & 41 & $19(11)^{\dagger}$ & $22(19)^{\ddagger}$ & 0.91 \\
\hline IBIS* & 6037 & 30 & 88 & $-{ }^{*}$ & $-^{*}$ & $-^{*}$ \\
\hline MORE [7] & 7705 & 40 & 54 & $22 / 2^{\ddagger}$ & 32 & 0.35 \\
\hline
\end{tabular}

${ }^{*}$ As of 1 December 1999 (ongoing and still blinded). ${ }^{\dagger}$ Tamoxifen $>1$ year. ${ }^{\ddagger} 2: 1$ ratio of raloxifene:placebo in MORE study.

Table 3

Demographic data from the five breast cancer prevention trials

\begin{tabular}{|c|c|c|c|c|c|c|c|}
\hline \multirow[b]{2}{*}{ Trial } & \multirow[b]{2}{*}{$\begin{array}{c}\text { Age } \\
\text { (median; years) }\end{array}$} & \multirow[b]{2}{*}{$\begin{array}{l}\text { Age }<50 \\
\text { years (\%) }\end{array}$} & \multirow{2}{*}{$\begin{array}{l}\text { First-degree } \\
\text { relative with breast } \\
\text { cancer (\%) }\end{array}$} & \multirow{2}{*}{$\begin{array}{l}\text { Two or more } \\
\text { relatives with } \\
\text { breast cancer (\%) }\end{array}$} & \multicolumn{2}{|c|}{ Compliance (\%) } & \multirow[b]{2}{*}{$\begin{array}{l}\text { HRT use on } \\
\text { study (\%) }\end{array}$} \\
\hline & & & & & $\begin{array}{l}\text { Tamoxifen/ } \\
\text { raloxifene }\end{array}$ & Placebo & \\
\hline $\mathrm{RMH}\left[5^{\circ}\right]$ & 47 & 62 & 96 & 42 & 74 & 86 & 26 \\
\hline NSABP $\left[3^{\circ}\right]$ & $50-59$ & 37 & 76 & 33 & 76 & 80 & $<10$ \\
\hline Italian [6 $\left.6^{\circ}\right]$ & 51 & 38 & 12 & $?$ & 80 & 75 & 12 \\
\hline IBIS* & 50 & 51 & 91 & 30 & \multicolumn{2}{|c|}{74 at 4 years } & 22 \\
\hline MORE $\left[7^{\circ}\right]$ & 67 & Very few & $12^{+}$ & $?$ & 78 at 3 years & 75 & $10^{\ddagger}$ \\
\hline
\end{tabular}

${ }^{*}$ As of 1 December 1999 (accrual ongoing). 'Defined as 'family history of breast cancer'. " Raloxifene stopped when oestrogen started.

compliance only about half of the potential efficacy information is obtained. Compliance on tamoxifen was typically approximately 5-10\% less than that for placebo, which reflects the dropout rate due to side effects.

\section{Use of hormone replacement therapy}

Many women entering the four tamoxifen chemoprevention

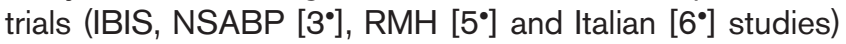
were taking hormone replacement therapy (HRT). In all but the NSABP study, they were able to continue HRT or could start if menopausal symptoms became intolerable. Thus, $14-26 \%$ of subjects had taken HRT in addition to tamoxifen or placebo in the non-US trials. HRT use was equally distributed between the two treatments in the $\mathrm{RMH}$ and Italian studies, and has not been reported to date in IBIS. Use of HRT was also proscribed in the MORE trial, but $16 \%$ had used it previously. The potential confounding effects of HRT in these studies is discussed below.

\section{Breast cancer reduction}

The early results of three tamoxifen studies have been reported (NSABP $\left[3^{\circ}\right], \mathrm{RMH}\left[5^{\circ}\right]$ and Italian [6 $6^{\circ}$ studies) and are summarized in Table 2 and Figure 1. The IBIS trial is due to recruit until the end of 2000 , and will report 1 or
2 years later. The NSABP study showed a clear dramatic reduction (odds ratio [OR] 0.51, 95\% confidence interval [Cl] 0.39-0.66) in the incidence of invasive cancers in the tamoxifen arm. This result is very similar to the reduction in contralateral tumours reported in the overview of tamoxifen adjuvant trials $\left[4^{\circ}\right]$. The $\mathrm{RMH}$ and Italian trials did not show appreciable treatment effects. In the $\mathrm{RMH}$ trial [5*] the incidence curves for invasive cancers for the two arms are superimposable. When the Italian trial $\left[^{\circ}{ }^{\circ}\right.$ was analyzed according to whether subjects took medication for longer than 1 year, there were indications of an effect (19 versus 11, OR 0.58), although the numbers are small and this was an unplanned subgroup comparison. Also, there was one case of breast cancer in the tamoxifen + HRT group, compared with eight in the placebo + HRT group $(P=0.02)$, suggesting that tamoxifen is particularly effective in preventing cancers that are associated with exogenous oestrogen use.

The MORE trial [ $\left.7^{\circ}\right]$ showed the greatest reduction in breast cancer incidence (relative risk $0.35,95 \% \mathrm{Cl} 0.21-0.58$ ) on the basis of 22 cancers in 5129 women assigned to raloxifene (at 60 or $120 \mathrm{mg}$ ) and of 32 cancers in 2576 women assigned to placebo. The reduction in invasive breast 
Figure 1

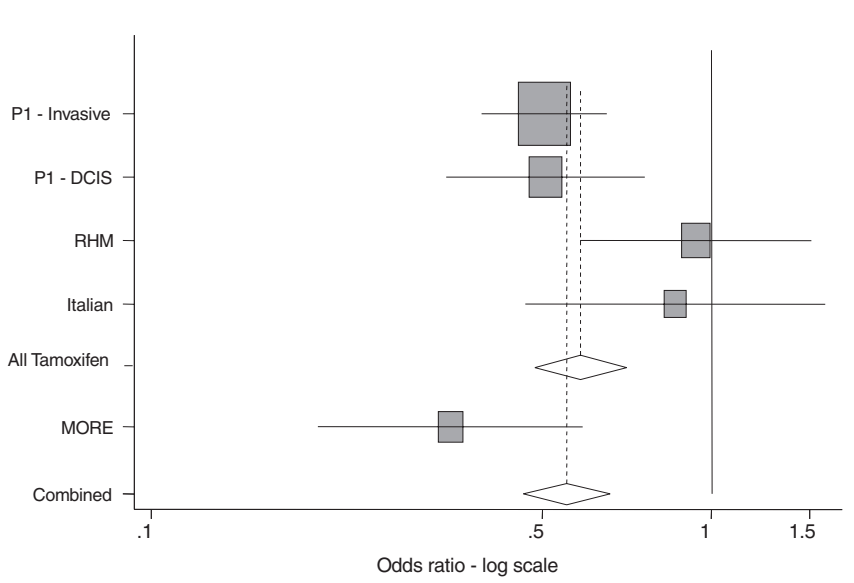

Forest plot of estimates of breast cancer incidence reduction for the prevention trials. Summary estimate for tamoxifen trials is OR 0.58 (95\% Cl 0.48-0.71), and for all trials is OR 0.55 (95\% Cl 0.46-0.66), both with $P<0.001$. Heterogeneity tests give $P=0.07$ for all tamoxifen trials, including the NSABP Prevention $1(\mathrm{P} 1)$ study in situ strata, $P=0.04$ without this strata, and $P=0.03$ for all five strata. In situ cancers are included in the totals, except for $\mathrm{P} 1$, for which they are

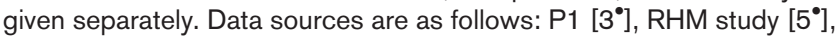
Italian study $\left[6^{\circ}\right]$ and MORE $\left[7^{\circ}\right]$.

tumours was even greater, giving an OR of $0.24(95 \% \mathrm{Cl}$ $0.13-0.44)$ on the basis of 13 versus 27 cancers.

Very few patients have died in any of these trials, and even

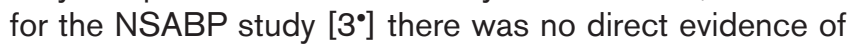
a reduction in breast cancer mortality (six patients on placebo versus three patients on tamoxifen).

\section{Oestrogen receptor-negative tumours}

The incidence reduction in the NSABP study [3"] and MORE trial $\left[7^{\circ}\right]$ is restricted to oestrogen receptor (ER)positive tumours. In the NSABP study the reduction was

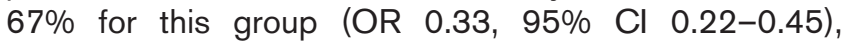
whereas there was a slight increase in ER-negative tumours (OR 1.22, 95\% Cl 0.74-2.03). Similarly in the MORE trial ER-positive tumours were reduced by $90 \%$ (OR $0.10,95 \% \mathrm{Cl} 0.04-0.24$ ), but there was little effect on ER-negative tumours (OR 0.88, 95\% Cl 0.26-3.0).

\section{Side effects}

\section{Endometrial cancer}

Endometrial cancer is the most clearly recognized, if rare side effect of tamoxifen. Several case reports and case-control studies have found an effect [9], albeit of highly variable size. The overview of adjuvant trials [4 $\left.{ }^{\circ}\right]$ found 92 endometrial cancers in users of tamoxifen, compared with 32 cancers in control individuals, giving an $\mathrm{OR}$ of 2.58 (95\% Cl 1.9-3.3). In the NSABP study [3"] the excess was 36 cases versus 13 , leading to a very similar OR of $2.53(95 \% \mathrm{Cl} 1.35-4.97)$. All of the cases identified were International Federation of Gynecology and Obstetrics stage I, except one of the control patients who was stage IV, and is the only patient reported to have died from endometrial cancer. No increase in endometrial cancer was found for women younger than 50 years, and the OR for older women was 4.01 . In the RMH study [5"] there were four cases of endometrial cancer in the tamoxifen arm versus one in the control individuals, and of course there were none in the Italian study [6 $6^{\circ}$ because all subjects had had a hysterectomy. No data are available for the IBIS study. In the MORE trial [7"] there was no effect on endometrial cancer on the basis of six cases in the combined raloxifene groups versus four in the control group.

\section{Other cancers}

No cancers other than endometrial were elevated in the

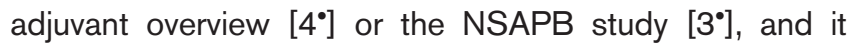
seems increasingly likely that tamoxifen has a minimal effect on the development of other tumours, in contrast to early concerns about liver and colorectal tumours [10-12].

\section{Vascular events}

Reports from women taking tamoxifen for breast cancer suggested an increase in vascular events, but the relation to tamoxifen by itself was in question because of the potential confounding effect of chemotherapy and surgery.

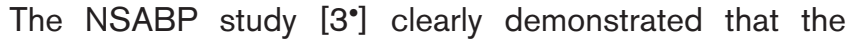
tamoxifen alone can increase the risk of these events, with a $59 \%$ increase in strokes ( 1.45 versus 0.92 events per 1000 patient-years), a threefold increase in pulmonary embolism ( 0.69 versus 0.23 cases per 1000 patientyears) and a $60 \%$ increase in deep vein thrombosis (1.34 versus 0.84 cases per 1000 patient-years). Three of the nine pulmonary embolisms in the tamoxifen group were fatal. All of these excess risks were again confined to women aged 50 years or older.

Similar results were reported in the Italian trial $\left[6^{\circ}\right]$, with 38 vascular events on tamoxifen and 18 on placebo $(P=0.005)$, although most of these were superficial phlebitis and there were only nine were deep vein thromboses (six versus three, respectively) and two pulmonary embolisms (one versus one, respectively).

Thromboembolic disease was also elevated with raloxifene in the MORE trial $\left[7^{\circ}\right]$. The magnitude was again about threefold (OR 3.1, 95\% Cl 1.5-6.2) based on a rate of $3 / 1000$ in the placebo arm and 9.5/1000 in the combined raloxifene arms.

\section{Menopausal symptoms}

Both the RMH study and NSABP study have shown a clear increase in menopausal symptoms (Table 4), the most common of these was hot flushes, which rose from 17 to $33 \%$ in the RMH study [13] and from 65 to $78 \%$ in the NSABP study [14]. Vaginal discharge and menstrual 
irregularities were also more common in both trials. Less specific factors such as weight gain, headaches, or depression, which have been suggested as being related to tamoxifen, were not elevated on tamoxifen in either trial.

\section{Other negative effects}

A few other effects, both positive and negative, appear to be related in a small degree to tamoxifen exposure. The NSABP study [14] has reported a $14 \%$ increase in cataracts that was of marginal statistical significance, and the RMH trial [15] has suggested a possible loss of bone in premenopausal women.

\section{Other beneficial effects \\ Bone}

Several studies have shown that tamoxifen has beneficial effects on bone tumour markers and bone mineral density in postmenopausal women (for review, see [8]). It may take some time for this to be fully translated into clinical benefit because of the relatively young age of the women in these trials. However, a nonsignificant $19 \%$ of fractures at sites associated with osteoporosis (hip, Colles radius, spine) has already been seen in the NSABP study [3], but no reduction in the much larger number of other fractures was observed.

Raloxifene has been shown to improve bone biomarkers [16], and recent data [17] show a reduction in vertebral fractures.

\section{Cardiovascular}

There is little doubt that tamoxifen reduces low-density lipoprotein cholesterol by about 20\% (for review, see [8]). The early reports of reductions in cardiovascular disease in adjuvant trials $[18,19]$ have yet to be confirmed in the prevention trials, however. This again may relate to the younger age distribution.

\section{Discussion}

The aim of this short review was to examine the available results from the prevention trials and to attempt to explain

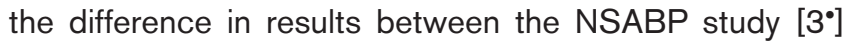
and the European trials (IBIS and $\left[5^{\circ}-7^{\circ}\right]$ ) that have been reported to date. At this stage there is more agreement on side effects than on efficacy. The NSABP study is strongly positive. The strength of these results is reflected in the $P$ value for the main effect (reduction in invasive tumours by tamoxifen, $P<0.00001$ ), and indicates the tiny chance that the result arose by chance. Thus, given the size of the effect, there can be little doubt that tamoxifen reduces the incidence of breast cancer, and possible reasons for the initial negative results from the European trials need to be examined carefully.

No factor clearly explains these differences, and in terms of entry criteria the $\mathrm{RMH}\left[5^{\circ}\right]$ and Italian $\left[6^{\circ}\right]$ trials are more
Table 4 Common side-effects reported in two tamoxifen
chemoprevention trials

\begin{tabular}{llccc}
\hline Side effect & Trial & $\begin{array}{c}\text { Tamoxifen } \\
(\%)\end{array}$ & $\begin{array}{c}\text { Placebo } \\
(\%)\end{array}$ & $P$ \\
\hline Hot flushes & RMH & 34 & 20 & $<0.001$ \\
& NSABP & 78 & 65 & $<0.001$ \\
Vaginal discharge & RMH & 16 & 4 & $<0.001$ \\
& NSABP & 55 & 34 & $<0.001$ \\
Menstrual & RMH & 14 & 9 & 0.002 \\
irregularities & NSABP & 22 & 21 & NS \\
(bleeding) & & & & \\
Nausea & RMH & 6 & 10 & 0.02 \\
Headaches & RMH & 12 & 14 & NS \\
Mood change & RMH & 3 & 3 & NS \\
& NSABP & 11 & 12 & NS \\
Weight gain/loss & RMH & 7 & 11 & NS \\
& NSABP & 45 & 42 & NS \\
\hline
\end{tabular}

NS, not significant. Data for the RMH trial from [13]; Data for the NSABP study from $\left[3^{\circ}, 14\right]$.

different from each other than either are from the NSABP

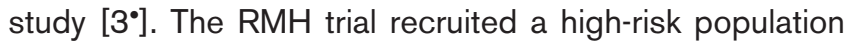
with predominantly a strong family history, whereas the Italian trial included a normal or even low-risk population (because of the removal of the ovaries in many cases).

One factor that the European trials share but was not

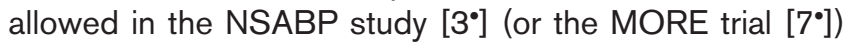
was concomitant HRT. Indirect observations suggest that HRT use in both arms may tend to give a greater benefit for tamoxifen, however. Because HRT is associated with an increased risk of ER-positive breast cancer, more endocrine-sensitive tumours might be expected in the absence of tamoxifen and these are the tumours that tamoxifen is particularly good at preventing. Indeed this was found for the Italian trial, in which there were eight cancers for HRT + placebo versus only one in the HRT + tamoxifen group.

A test for heterogeneity between the trials is not significant $(P=0.07)$ if the NSABP study in situ lesions are taken as a separate strata, and only marginally significant $(P=0.04)$ if they are excluded. Chance must still be considered as a serious explanation for the differences. The results are all consistent with a $42 \%$ reduction in breast cancer incidence, but the pooled estimate for the tamoxifen trials still has a $95 \% \mathrm{Cl}$ spanning anywhere from 30 to $55 \%$ reduction.

\section{Conclusion}

Perhaps the main conclusion is that there are no clear conclusions at this stage. The $\mathrm{RMH}$ trial $\left[^{\circ}\right]$ is relatively 
small and follow up in the Italian trial $\left[6^{\circ}\right]$ is relatively short.

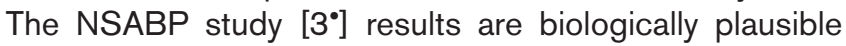
and in accord with the risk reduction seen in the contralateral breast in the adjuvant tamoxifen trials [ $\left.4^{\circ}\right]$. Overall, the data support a breast cancer incidence reduction of about $40 \%$, but the $\mathrm{Cl}$ is wide. It is still unclear what effect this will have on mortality, or indeed what the long-term effects will be on incidence. Uncertainties exist as to which women are most suitable for tamoxifen chemoprevention (BRCA1/BRCA2 mutation carriers, weaker family histories, women with hormonal risk factors) and about the potential interaction with HRT. It will be important to continue the follow up of the European trials. The IBIS trial will be crucial in resolving the value of tamoxifen and, if positive, it will be important not to prematurely break the randomization code in order to determine the long-term benefits of tamoxifen prophylaxis.

\section{References}

Articles of particular interest have been highlighted as:

- of special interest

- of outstanding interest

1. Cuzick J, Baum M: Tamoxifen and contralateral breast cancer [letter]. - $\quad$ Lancet 1985, ii:282.

This is the first report that tamoxifen use reduces contralateral tumours in women with breast cancer.

2. Cuzick J, Wang DY, Bulbrook RD: The prevention of breast cancer. Lancet 1986, i:83-86.

The rationale and initial detailed proposal for a tamoxifen breast cancer prevention trial is described.

3. Fisher B, Costantino JP, Wickerham LD, et al: Tamoxifen for preven-

- tion of breast cancer: report of the National Surgical Adjuvant Breast and Bowel Project P-1 Study. J Natl Cancer Inst 1998, 90:1371-1388.

A report on breast cancer reduction and on other major end-points in the NSABP prevention trial is presented.

4. Early Breast Cancer Trialists' Collaborative Group (EBCTCG):

- Tamoxifen for early breast cancer: an overview of the randomised trials. Lancet 1998, 351:1451-1467.

This is a comprehensive meta-analysis on results of adjuvant tamoxifen treatment in women with early breast cancer.

5. Powles T, Eeles R, Ashley S, et al: Interim analysis of the incidence - of breast cancer in the Royal Marsden Hospital tamoxifen randomised chemoprevention trial. Lancet 1998, 352:98-101.

This interim analysis indicates no reduction of breast cancer incidence in the $\mathrm{RMH}$ trial.

6. Veronesi U, Maisonneuve $\mathrm{P}$, Costa $\mathrm{A}$, et al: Prevention of breast

- cancer with tamoxifen: preliminary findings from the Italian randomised trial among hysterectomised women. Lancet 1998, 352:93-97.

This early report shows no reduction of incidence of breast cancer in the Italian prevention trial.

7. Cummings SR, Eckert S, Krueger KA, et al: The effect of raloxifene

- on risk of breast cancer in postmenopausal women. Results from the MORE randomized trial. JAMA 1999, 281:2189-2197.

This is a report of the effect of 3 years of raloxifene treatment on breast cancer, with some data on side effects.

8. Cuzick J: Chemoprevention of breast cancer with tamoxifen. In: Chemoprevention in Cancer Control, IARC Scientific Publications No. 136. Edited by Hakama M, Beral V, Buiatti E, Faivre J, Parkin DM. Lyon: IARC, 1996:95-109.
9. IARC: Some pharmaceutical drugs. In: IARC Monographs on the Evaluation of Carcinogenic Risks to Humans, vol 66. Lyon: IARC 1996:253-365.

10. Han X, Liehr J: Induction of covalent DNA adducts in rodents by tamoxifen. Cancer Res 1992, 52:1360-1363.

11. Greaves $P:$ Ten year carcinogenicity study of tamoxifen in Alderley Park wister-derived rats. Cancer Res 1993, 53:3919-3924.

12. Rutqvist LE, Johansson $H$, Signomklao $T$, et al: Adjuvant tamoxifen therapy for early stage breast cancer and second primary malignancies. J Natl Cancer Inst 1995, 87:645-651.

13. Powles TJ, Tillyer CR, Jones AL, et al: Prevention of breast cancer with tamoxifen: an update on the Royal Marsden Hospital pilot programme. Eur J Cancer 1996, 26:680-684.

14. Day R, Ganz PA, Costantino JP, et al: Health-related quality of life and tamoxifen in breast cancer prevention: a report from the National Surgical Adjuvant Breast and Bowel Project P-1 Study. $J$ Clin Oncol 1999, 17:2659-2669.

15. Powles TJ, Hickish T, Kanis A, et al: Effect of tamoxifen on bone mineral density measured by dual-energy $\mathrm{X}$-ray absorptiometry in healthy premenopausal and postmenopausal women. J Clin Oncol 1996, 14:78-84.

16. Delmas PD, Bjarnason NH, Mitlak BC, et al: Effects of raloxifene on bone mineral density, serum cholesterol concentrations, and uterine endometrium in postmenopausal women. $N$ Engl $\mathrm{J}$ Med 1997, 337:1641-1647.

17. Ettinger $\mathrm{B}$, Black $\mathrm{DM}$, Mitlak $\mathrm{BH}$, et al: Reduction of vertebral fracture risk in postmenopausal women with osteoporosis treated with raloxifene. JAMA 1999, 282:637-645.

18. McDonald CC, Stewart HJ for the Scottish Breast Cancer Committee: Fatal myocardial infarction in the Scottish adjuvant tamoxifen trial. Br Med J 1991, 303:435-437.

19. Rutqvist LE, Mattson A: Cardiac and thromboembolic morbidity among postmenopausal women with early-stage breast cancer in a randomised trial of adjuvant tamoxifen. J Natl Cancer Inst 1993, 85:1398-1406.

Author's affiliation: Department of Mathematics, Statistics and Epidemiology, Imperial Cancer Research Fund, London, UK

Correspondence: Jack Cuzick, Department of Mathematics, Statistics and Epidemiology, Imperial Cancer Research Fund, 61 Lincoln's Inn Fields, London, WC2A 3PX, UK. Tel: +44 0207269 3006; fax: +44 0207269 3429; e-mail: cuzick@icrf.icnet.uk 